Research Article

\title{
Thermal Stability of BFRP Laminated composites:An Accent on Mechanical Behavior
}

\author{
J. Alexander ${ }^{\dot{A}^{*}}$ and BSM. Augustine $e^{\dot{A}}$ \\ ${ }^{\dot{A}}$ Department of Aeronautical Engineering,Sahtyabma University,OMR, Chennia-6001199
}

Accepted 10 January 2014, Available online 01 February 2014, Special Issue-2, (February 2014)

\begin{abstract}
Thermoplastic fiber reinforced plastic composites are widely used in the construction of primary structures of aircraft which will undergo through thermal loading throughout their mission. These temperatures will affect the mechanical behavior of composites much. Basalt fiber reinforced plastic (BFRP) composites are having very good unique mechanical properties than GFRP. Therefore BFRP can be used instead of GFRP in aircraft construction. The objective of this research work is to characterize the tensile, compressive, bending, shear and impact behavior of the BFRP when exposed to various temperatures like room temperature $50^{\circ} \mathrm{C}, 80^{\circ} \mathrm{C},-22^{\circ}$ Cand aging conditions. The experimental results show the mechanical characteristics are much affected due to temperature.
\end{abstract}

Keywords: BFRP, various temperature conditions, mechanical characteristics.

\section{Introduction}

The continuous basalt fibers are manufactured from naturally occurring inert volcanic rock which are available throughout the world. These fibers are having excellent mechanical, thermal, chemical properties which are suitable for various structural applications. The properties of BFRP are comparable with the properties of GFRP. GFRP are widely used for various structural applications including aero industry due to their higher specific strength, thermal properties, stiffness, better chemical properties. These performances also can be seen in BFRP, even better than GFRP. Many researchers have investigated the properties of BFRP and their applications. Militky et al has tempered the basalt fibers at various temperature conditions and found the tensile strength and compared the same with glass fiber and proved basalt fibers are better . Lopresto has investigated the mechanical properties of BFRP at room temperatur. It was demonstrated that the interfacial region of basalt fiber reinforced polymer was more susceptible than that of glass fiber reinforced composites after salt water immersion and moisture absorption and an excellent interfacial shear strength was found . Kim et al has investigated the effects of surface treatment of a basalt fiber by low-temperature atmospheric oxygen plasma on the interlaminar fracture behavior of basalt/epoxy woven composites and showed that the wettability of the basalt fiber was remarkably increased. Tehrani et al have conducted experimental investigation on the low velocity impact behavior of homogenous and hybrid composite laminates reinforced by basalt-nylon intra-ply fabrics. The results indicate that impact performance of these composites is significantly affected by the nylon/basalt fiber content. Manikandan et al have suggested that acid treated basalt fibers improves its strength..In composite laminate fabrication processes, the compression molding process is the best process..

From the literature review, only limited investigation have been carried out on the basis of BFRP yet. This paper focuses on the variations of the strength of BFRP due to temperature variations and aging. As per literature review compression molding provides good strength, using compression molding $300 \mathrm{~mm} \times 300 \mathrm{~mm}$ dimension laminates were fabricated and specimens were cut using special cutter as per ASTM standards. The chemical combination of the BFRP is determined by using Fourier Transform Infra-Red spectroscopy (FTIR). Specimens are kept at various temperature conditions from $-22^{\circ} \mathrm{C}$ to $80^{\circ} \mathrm{C}$. Also the specimens were kept at ageing condition. The tensile test, bending test, shear test and compression tests were carried out by using Computerized Universal Testing Machine (UTM).Impact strengths were determined by using charpy impact testing machine. The mechanical behavior of BFRP at various temperature is found out and this material is suggested to use various applications like Automobile, mechanical industries and where ever various temperature variations are involved especially in the manufacture of aircrafts.

\section{Specimen preparation and experimental procedures}

\subsection{Materials}

Basalt Owen fabric (plain weave with surface density 
$220 \mathrm{~kg} / \mathrm{cm} 2$ ) was imported from Incotelogy, Germany and the epoxy LY556 and the hardener Aradur Hy 951 were purchased from Javanthy Enterprises, Chennai.

\subsection{Fabrication of BFRP laminates}

BFRP laminates were fabricated by using compression moulding machine available at Indian Institute of Technology (IIT), Chennai. Fiber mats are cut into $300 \mathrm{~mm} \times 300 \mathrm{~mm}$ size. 16 layers of fabrics were laid. Resin was taken 2 times that of fiber by weight. Hardener 1/10th weight of resin was added with the resin in order to activate the curing. This mixture was homogenized by using a stirrer and applied over the fabric. This is kept in the bed of the compression molding machine and compressed hydraulically at a pressure of 30 bar and $60^{\circ} \mathrm{C}$ temperature for about 3 hours duration. Then the laminate is taken out of the machine and cured at room temperature for about 24 hours. Volume fractions of the fiber and matrix were determined by using burnt test as per ASTM D-2584 standard. Tensile test, bending test, shear test and impact test specimen were cut from this laminate and a set of specimen were kept inside a hot Owen at $50^{\circ} \mathrm{C}$ at around 2 hours, another set of specimen at $50^{\circ} \mathrm{C}$ hours duration, another set at $80^{\circ} \mathrm{C}$ for 2 hours, another set at $80^{\circ} \mathrm{C}$ for 3 hours and another sets at $-22^{\circ} \mathrm{C}$ in a cold freezer which are available at the chemical laboratory, Sathyabama University, Chennai. For each test three specimen were taken. One set of all types of test specimen were undergone through ageing. The aging process is given below 30 minutes at $50^{\circ} \mathrm{C}$,- 10 minutes at room temperature for cooling- 30 minutes at $60^{\circ} \mathrm{C}-10$ minutes at room temperature for cooling- 30 minutes at $70^{\circ} \mathrm{C}-10$ minutes at room temperature for cooling- 30 minutes at $80^{\circ} \mathrm{C}-10$ minutes at room temperature for cooling.

\subsection{Fourier Transform Infra-Red spectrometer (FTIR) Test}

FTIR test is carried out to find out the chemical combination in the fabricated BFRP laminate. The constituents spectrum is given in Fig. 1 and the functional groups are tabulated in Table1

\section{Results and Discussions}

BFRP specimens prepared as per ASTM standards and at room temperature, $50^{\circ} \mathrm{C}$ (2hrs), $50^{\circ} \mathrm{C}(3 \mathrm{hrs}), 80^{\circ} \mathrm{C}(2 \mathrm{hrs})$, $80^{\circ} \mathrm{C}(3 \mathrm{hrs}),-22^{\circ} \mathrm{C}$ and aging conditions were undergone through tensile, compressive, flexure, shear and impact tests using standard machines. All the tests data were recorded through graphs. The results are discussed here below. The recorded data comprises of average of three or more tests. The mechanical properties of BFRP at various temperature conditions were compared with the mechanical properties at room temperature. The percentages of variations are tabulated in tables 3-7.

It was found that at $50^{\circ} \mathrm{C}$ treatment led to statistically significant increase of tensile strength, (Fig: 2) but at $80^{\circ} \mathrm{C}$ the tensile strength decreased even at low temperature strength decreased. Probably, the changes of these properties are based on the changes in the crystalline structure of fibers and the molecular changes of resins. At low temperature the BFRP have become brittle and has lost its strength. But it is observed that the tensile behavior is best at the aging condition.

The failure modes of BFRP at various loading conditions are fiber breakage at tension, fiber buckling and delamination at compression. The failure modes are very complicated at flexure. In flexure test, Interlaminar shear strength (ILSS) predicts the bond strength between the fiber and matrix. If the transverse loading exceeds ILSS, failure will occur in between the fibers and matrix.

\subsection{Mechanical Characterization}

Tensile tests were conducted to evaluate the strength(maximum stress) of the BFRP using a UTM(TUE-CN-1000) with a cross head speed of $2 \mathrm{~mm} /$ min according to ASTM D 3039/D 3039M-00. Three samples were taken from each combination,(i.e 3 specimen for room temperature, 3 specimen for room temperature, 3 specimen for $50^{\circ} \mathrm{C}(2 \mathrm{hrs})$, 3 specimen for $50^{\circ} \mathrm{C}$ (3hrs), 3 specimen for $80^{\circ} \mathrm{C}$ ( $\left.2 \mathrm{hrs}\right), 3$ specimen for $80^{\circ} \mathrm{C}$ ( $3 \mathrm{hrs}$ ) and 3 specimen for aging) and the results were read through Data Acquisition System supplied by fine spavy Associates and engineers pvt. Ltd, Miraj from the computer attached to the UTM. Then the results were averaged. This showed the tensile strength of the polymer composites. In the same way flexural test was conducted as per ASTM D 790-03 for all temperature conditions by using UTM. Also the compression tests conducted for all temperature conditions using UTM as per ASTM D 69502a standard. The characteristics of specimen are tabulated in table 2 .

An impact test was used to determine the amount of energy that was required to break the specimen. Notched Izod Impact test was conducted to study the impact energy according to ASTM D256. The specimens were kept in a cantilever position, and a pendulum has swung around to break the specimen. The impact energy $(\mathrm{J})$ was calculated using a dial gauge that was fitted on the machine. Five samples were taken for each temperature conditions, and the results were averaged.

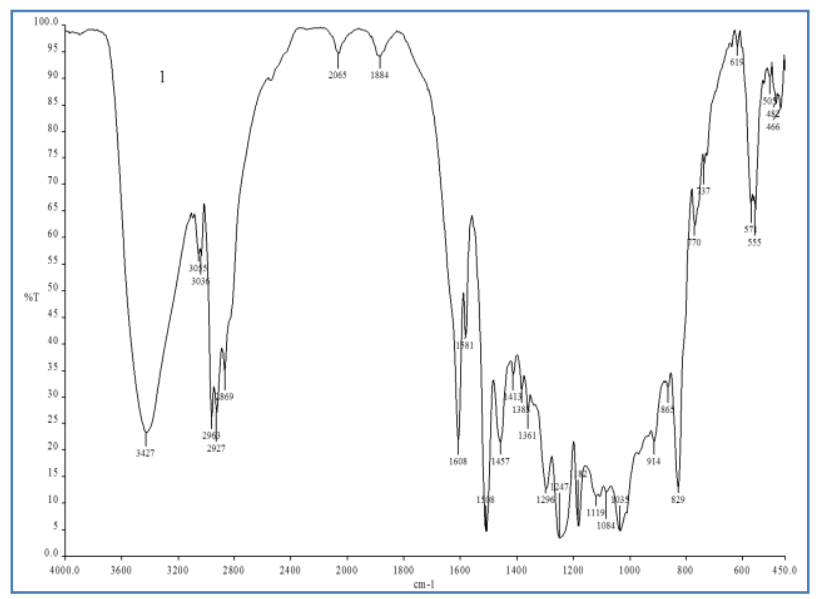

Fig 1: shows the wave number and percentage of transmission of the constituents 
Table 1 FT IR -Functional Group \&Wave number

\begin{tabular}{|l|l|l|}
\hline Region & Functional Group & Wave Number $\left(\mathbf{c m}^{-\mathbf{1}}\right)$ \\
\hline 1. & OH & $3800-2700$ \\
\hline 2. & CH & $3000-2850$ \\
\hline 3. & Anhydride & $1800-1830$ \\
\hline 4. & C-C,C-N triple bonds & $2000-2500$ \\
\hline 5. & C=O (Acid) & $1850-1600$ \\
\hline 6. & C=C & $1900-1500$ \\
\hline 7. & Aromatic Compounds & $1600-1450$ \\
\hline 8. & Nitro Group & $1400-1300$ \\
\hline 9. & C-C & $1300-800$ \\
\hline 10. & Arenes & $700-600$ \\
\hline 11. & Synthetic Clays & $400-600$ \\
\hline
\end{tabular}

Table 2 Standards and dimensions of specimen for all kinds of tests

\begin{tabular}{|c|c|c|c|c|}
\hline Test & Standard of Test & $\begin{array}{l}\text { Thickness } \\
(\mathrm{mm})\end{array}$ & $\begin{array}{l}\text { Width } \\
(\mathrm{mm})\end{array}$ & $\begin{array}{l}\text { Gauge } \\
\text { length }(\mathrm{mm})\end{array}$ \\
\hline Tensile & $\begin{array}{l}\text { ASTM } \\
\text { D3039/D3039M-00 }\end{array}$ & 2.6 & 25 & $\begin{array}{l}100 \quad(280 \\
\text { length) }\end{array}$ \\
\hline Compression & ASTM D 695-02a & 4 & 12.7 & 79 \\
\hline Flexural & ASTM D 790-03 & 2.6 & 13 & 40 \\
\hline Shear & $\begin{array}{l}\text { ASTM D2344/D } \\
2344 \mathrm{M}-00\end{array}$ & 10 & 20 & 60 \\
\hline
\end{tabular}

Temperature is also one of the factor which is having influence with Inter laminar shear stress. By generating pure shear stress case between the laminae, interlaminar shear failure can be induced. This is possible by using short beam shear(SBS) test.This tests are having many limitations.ILSS is determined by the specimen prepared based on the standard ASTM D 790-03.

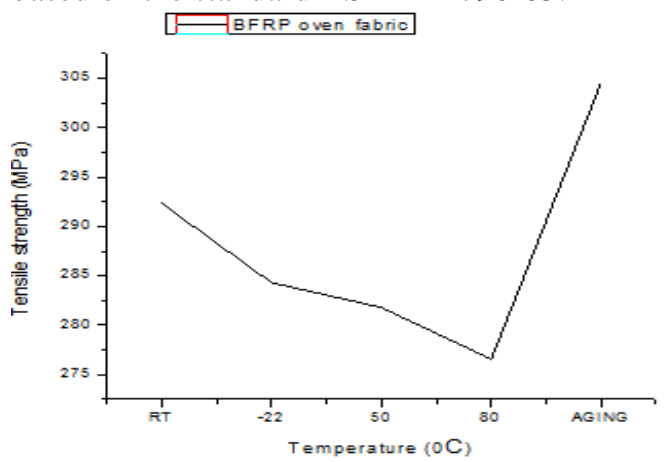

Fig 2: Tensile strengths (in $\mathrm{MPa}$ ) at various temperature conditions

\section{Compressive strength vs temperature}

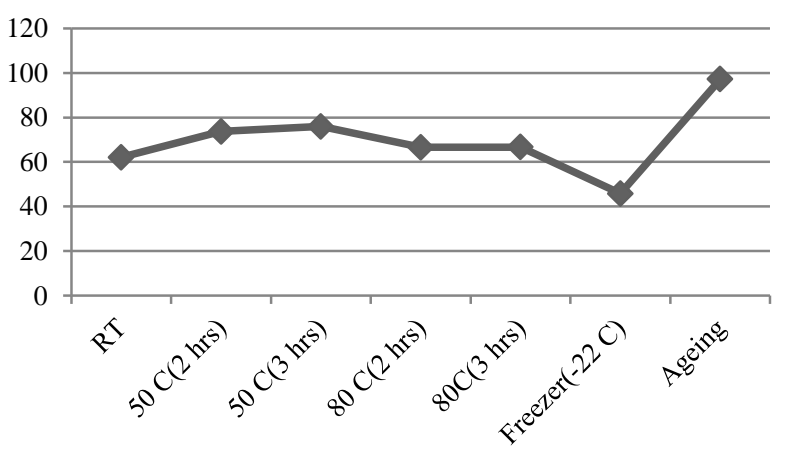

Fig 3: compressive strengths (in $\mathrm{MPa}$ ) at various temperature conditions
Fig 5 depicts the interlaminar shear strengths of BFRP at various temperature conditions. ILSS at $50^{\circ} \mathrm{C}$ is much higher than the Room temperature condition. At $50^{\circ} \mathrm{C}$ and the aging conditions the bond between the molecules of the epoxy resin is strengthened and correspondingly the adhesion factor of the epoxy and basalt is improved. The lower bond strength might have promoted fiber-matrix debonding at higher temperature $80^{\circ} \mathrm{C}$, for long term heating of BFRP and at freezing condition $\left(-22^{\circ} \mathrm{C}\right)$.

The failure mode of BFRP at compressive load is buckling and delamination. The stability of the composite and the bonding strengths are increased due to the aging condition.(Fig3) Consecutive changes in temperature

The impact characterization is essential for applications in the aeronautical, Marine and mechanical fields where crash aspects represent a key point. Most of the components in aircraft like landing gear struts, aircraft wings, and fuselage are subjected to impact loading.

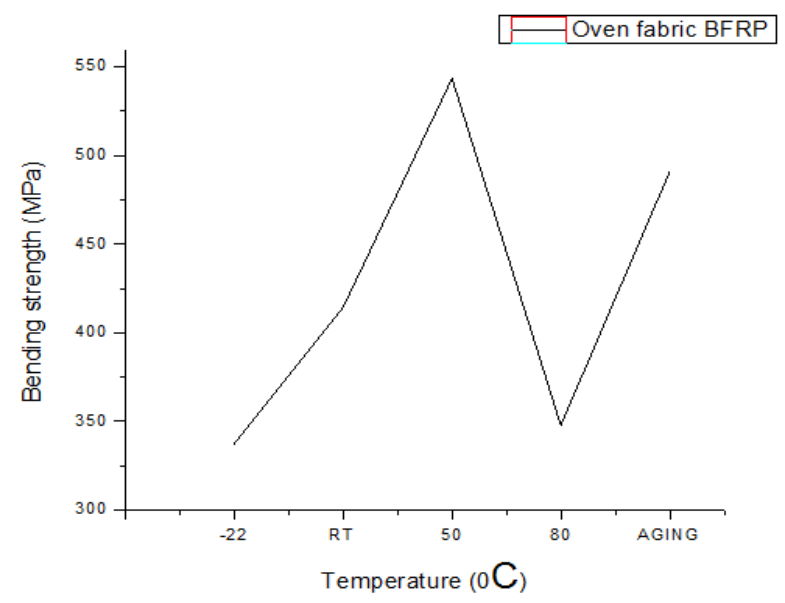

Fig 4: Bending strengths (in $\mathrm{MPa}$ ) at various temperature conditions

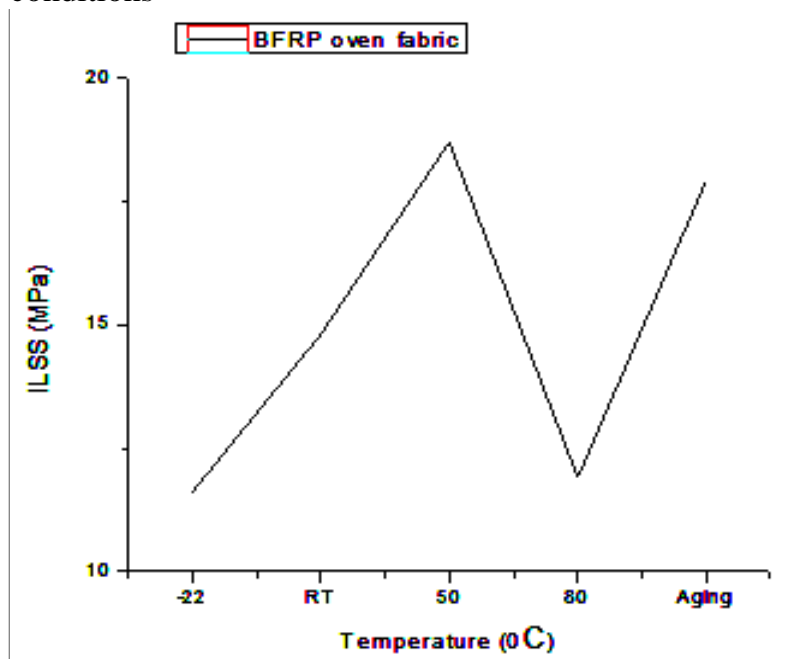

Fig5: ILSS (MPa) at various temperature conditions

The impact energy absorbing character decreases with increase of temperature. The reason is apart from matrix cracking and delamination which are felt at room temperature, the formation and growth of micro cracks. 
But at low temperature BFRP becomes more brittle. This shows the material becomes more brittle in high temperature. The intensity of damage increases. The same effect is seen even at low temperature. At freezing condition the material becomes brittle and micro cracks developed are reduced. But at low temperatures other forms of failure mechanisms takes place. At low temperature internal damage area increases which are associated with ply delamination. This shows that interlaminar bonds are degraded due to low temperature. Another failure mechanism at low temperature is fiber breakage near notch of the specimen.

Table3 Comparison of Tensile strength at room temperature with other temperature conditions

\begin{tabular}{|l|l|}
\hline comparision & Increased by \% \\
\hline $50^{\circ} \mathrm{C}(2 \mathrm{hrs})>\mathrm{RT}$ & $1.55 \%$ \\
\hline $50^{\circ} \mathrm{C}(3 \mathrm{hrs})>\mathrm{RT}$ & 2.44 \\
\hline $\mathrm{RT}>80^{\circ} \mathrm{C}(2 \mathrm{hrs})$ & -2.93 \\
\hline $\mathrm{RT}>80^{\circ} \mathrm{C}(3 \mathrm{hrs})$ & -0.535 \\
\hline $\mathrm{RT}>-22^{\circ} \mathrm{C}$ & -1.857 \\
\hline Ageing $>$ RT & 3.5 \\
\hline
\end{tabular}

Table4: Comparison of bending strength at room temperature with other temperature conditions

\begin{tabular}{|l|l|}
\hline comparision & Increased by \% \\
\hline $50^{\circ} \mathrm{C}(2 \mathrm{hrs})>\mathrm{RT}$ & $29.27 \%$ \\
\hline $\mathrm{RT}>50^{\circ} \mathrm{C}(3 \mathrm{hrs})$ & -1.79 \\
\hline $\mathrm{RT}>80^{\circ} \mathrm{C}(2 \mathrm{hrs})$ & -15.18 \\
\hline $\mathrm{RT}>80^{\circ} \mathrm{C}(3 \mathrm{hrs})$ & -14 \\
\hline $\mathrm{RT}>-22^{\circ} \mathrm{C}$ & -2.08 \\
\hline Ageing $>$ RT & 17.51 \\
\hline
\end{tabular}

Table5: Comparison of Interlaminar Shear strength at room temperature with other temperature conditions

\begin{tabular}{|l|l|}
\hline comparision & Increased by \% \\
\hline $50^{\circ} \mathrm{C}(2 \mathrm{hrs})>\mathrm{RT}$ & 30 \\
\hline $\mathrm{RT}>50^{\circ} \mathrm{C}(3 \mathrm{hrs})$ & -1.78 \\
\hline $\mathrm{RT}>80^{0} \mathrm{C}(2 \mathrm{hrs})$ & -15.18 \\
\hline $\mathrm{RT}>80^{\circ} \mathrm{C}(3 \mathrm{hrs})$ & -20.19 \\
\hline $\mathrm{RT}>-22^{0} \mathrm{C}$ & -1.78 \\
\hline Ageing $>$ RT & 17.09 \\
\hline
\end{tabular}

Fig $6 \& 7$ indicates the Field emission scanning electron microscope(FESEM) micro structure image of basalt epoxy laminated composite at high temperature post curing condition and delamination mode at high temperature respectively. The interfacial bond could be professed from the fractured surface. The cleaner,

Table6: Comparison of Compressive strength at room temperature with other temperature conditions

\begin{tabular}{|l|l|}
\hline comparision & Increased by \% \\
\hline $50^{\circ} \mathrm{C}(2 \mathrm{hrs})>\mathrm{RT}$ & 18.73 \\
\hline $50^{\circ} \mathrm{C}(3 \mathrm{hrs})>\mathrm{RT}$ & 22.34 \\
\hline $80^{\circ} \mathrm{C}(2 \mathrm{hrs})>\mathrm{RT}$ & 7.21 \\
\hline $80^{\circ} \mathrm{C}(3 \mathrm{hrs})>\mathrm{RT}$ & 7.21 \\
\hline $\mathrm{RT}>-22^{\circ} \mathrm{C}$ & -27.84 \\
\hline Ageing $>$ RT & 56.51 \\
\hline
\end{tabular}

smoother surface of the basalt fiber composites at high temperature indicates that the bond of resin and the fiber is better at high temperature. From the various SEM images taken it is evident that the various failure modes BFRP composites are due to matrix cracking, fiber full out and crushing of fibers.

Table7 Comparison of impact energy at room temperature with other temperature conditions

\begin{tabular}{|l|l|}
\hline comparision & Increased by \% \\
\hline $50^{\circ} \mathrm{C}(2 \mathrm{hrs})>\mathrm{RT}$ & -5.6 \\
\hline $50^{\circ} \mathrm{C}(3 \mathrm{hrs})>\mathrm{RT}$ & -4.3 \\
\hline $\mathrm{RT}>80^{\circ} \mathrm{C}(2 \mathrm{hrs})$ & -0.75 \\
\hline $\mathrm{RT}>80^{0} \mathrm{C}(3 \mathrm{hrs})$ & -2.28 \\
\hline $\mathrm{RT}>-22^{\circ} \mathrm{C}$ & -8.5 \\
\hline Ageing $>$ RT & -5.32 \\
\hline
\end{tabular}

\section{Conclusions}

The mechanical behavior of BFRP is very good when we compare the properties of GFRP. This material can be used in the place of GFRP in aero applications. Tensile strength, compressive strength, bending strength and ILSS

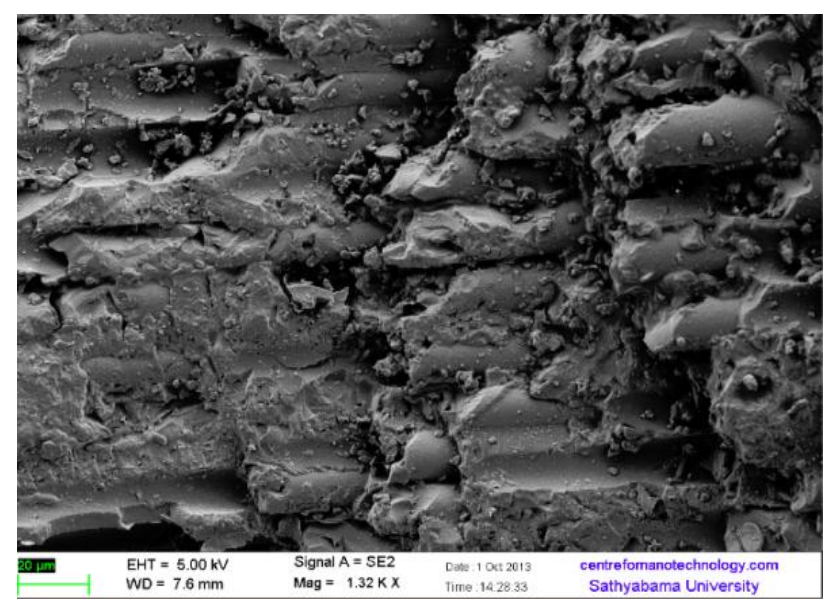

Fig6: Sem image of micro structure of BFRP at high temperature

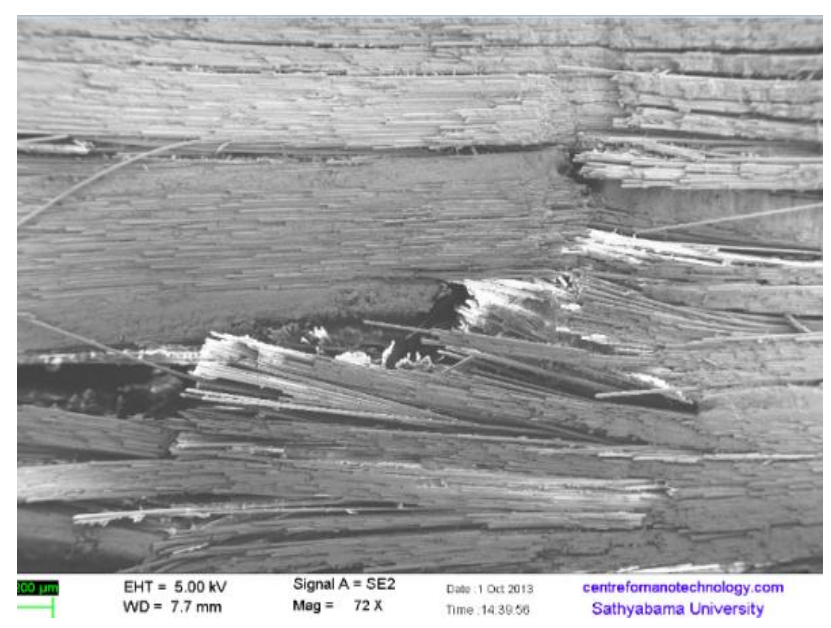

Fig7: Sem image of delamination failure mode of BFRP due to ILSS test at high temperature

102 | International Conference on Advances in Mechanical Sciences 2014 
are very high at the aging condition. One of the suggestion to improve mechanical properties of BFRP is aging(consequent heating and cooling) treatment can be given before it is used for some applications. More over if this material is used for the construction of aircrafts; the structure will be strengthened when the aircraft flies through various temperature regions. Results also show that BFRP loses its mechanical characteristics at freezing condition. Alternative treatment has to be given to improve the strengths for low temperature applications.

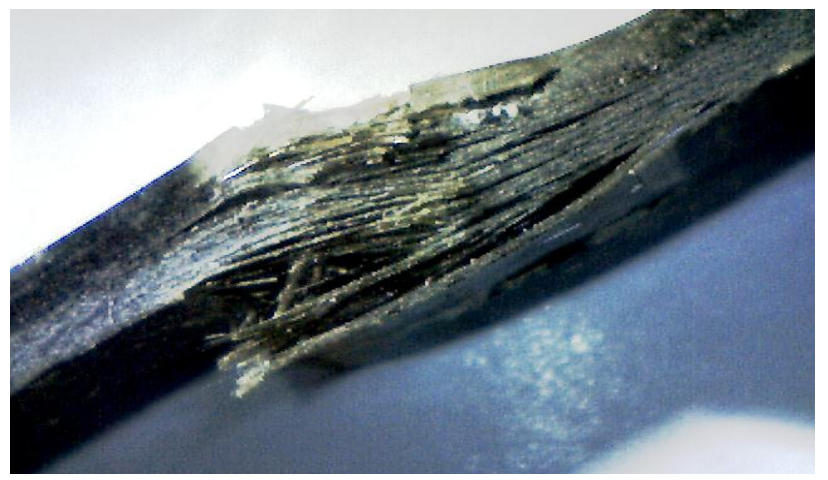

Fig8: Microscopic image of delamination failure mode of BFRP due to ILSS test at high temperature

\section{References}

Wei B, CAO H,Song S.(2010), Tensile behavior contrast of basalt and glass fibers after chemical treatment, MaterDes;31:424450 .

Wei B, CAO H,Song S(2010), environmental resistance and mechanical performance of basalt and glass fibers, Mater $\mathrm{Sci}$ Eng A-struct ,527:4708-15.

Pavlovski D, Mislavsky B, Antonov A (2007), CNG cylinder manufacturers test basalt fiber. Reinf Plast, 37-9.

Liu Q, Shaw MT, McDonnell AM, Parnas RS (2006). Investigation of basalt fiber composites mechanical properties for application in transportation, Polym Compos, 27:41-8.

Liu Q, Giffard HS, Shaw MT, McDonnell AM, Parnas RS(2005), Preliminary investigation of basalt fiber composite properties for applications in transportation. The official newsletter of the international institute for FRP in construction, vol. 2; p. 6-8.

Szabo JS, Czigany T(2003), Static fracture and failure behavior of aligned discontinuous mineral fiber reinforced polypropylene composites, Polym Test ,22:711-9.

Artemenko SE(2003), Polymer composites materials made from carbon, basalt and glass fibers, structures and properties, Fiber Chem ,35:226-9.
Jiri Militk_y , Vladim_1r Kovacic_, Jitka Rubnerov(2002), Influence of thermal treatment on tensile failure of basalt fibers, Engineering Fracture Mechanics 69 ,PP1025-1033

V. Lopresto, C. Leone, I. De Iorio(2011) ,Mechanical characterisation of basalt fibre reinforced plastic Composites: Part B 42 ,PP717-723.

Lisakovski AN, Tsybulya YL, Medvedyev AA(2001). Yarns of basalt continuous fibers.In: Proceedings of the fiber society, Raleigh, NC, USA;

Intrec Polymers Ltd. Basalt fibre reinforcements offer improved surface finish. Additive for polymers. Published by Elsevier Science Ltd; $2003 \quad$ [12: 3. ISSN:03063747,doi:10.1016/S0306-3747(03)00003-4].

M.T. Kim, M.H. Kim, K.Y. Rhee, S.J. Park(2011), Study on an oxygen plasma treatment of a basalt fiber and its effect on the interlaminar fracture property of basalt/epoxy woven composites, Composites: Part B 42 ,PP499-504.

Majid Tehrani Dehkordi, Hooshang Nosraty ,, Mahmood Mehrdad Shokrieh , Giangiacomo Minak ,Daniele Ghelli(2010), Low velocity impact properties of intra-ply hybrid composites based on basalt and nylon woven fabrics, Materials and Design 31;PP 3835-3844.

V. Manikandan, J.T. Winowlin Jappes , S.M. Suresh Kumar,Amuthakkannan(2012), investigation of the effect of surface modifications on the mechanical properties of basalt fibre reinforced polymer composites Composites: Part B 43,PP 812-818.

Amico SC, Angrizani CC, Drummond ML. Influence of the stacking sequence on the mechanical properties of glass/sisal hybrid composites. doi:10.1177/0731684408096 430.

Mohanthy AK, Wibowo A, Misra M, Drzal LT(2004). Effect of process engineering on the performance of natural fiber cellulose acetate biocomposites. Composites Part 1-Appl Sci ,35(3):PP1781-873.

Wanjun L, Drazal LT, Mohanthy AK, Misra M(2007). Influence of processing methods and fiber length on physical properties of kenaf fiber reinforced soy based biocomposites. Composites Part $B$,38(11):352-59.

Salvatore Carmisciano, Igor Maria De Rosa , Fabrizio Sarasini , Alessio Tamburrano , Marco Valente(2011), Basalt woven fiber reinforced vinylester composites: Flexural and electrical properties.Materials design, Elsevier publications, $\mathrm{PP}$ 337-342.

Rosselli F, Santare MH(1997). Comparison of the short beam shear (SBS) and interlaminar shear device (ISD) tests. Composites Part A ,28:PP587-94.

Abali F, Pora A, Shivakumar K(2003). Modified short beam shear test for measurement of interlaminar shear strength of composites. J Compos Mater ;37:PP453-64. 